\title{
Development of a Virtual Learning Environment (VLE) During the COVID -19 Pandemic: A Study with special reference to Advanced Technological Institute
}

\author{
M. R. M. Nowfeek ${ }^{1}$, Dr. Lakmal Rupasinghe ${ }^{2}$ \\ ${ }^{I}$ Department of Information Technology, ATI-Sammanthurai, Sri Lanka Institute of Advanced Technological Education \\ ${ }^{2}$ Faculty of Computing, Sri Lanka Institute of Information Technology (SLIIT)
}

\begin{abstract}
In this Covid-19 pandemic, Information and communication technology (ICT) plays a significant role and IT solutions such as the Virtual Learning Environments (VLE) have become vital. In pandemic situation, the Virtual Learning Environment (VLE) integrates many tools to provide higher educational institutions with an effective and efficient method to share, manage, store, and enhance their traditional approach of teaching. The implementation of VLE During the COVID -19 Pandemic has become a need at Advanced Technological institute in the learning and teaching environment. Although there is an increased willingness to its widespread implementation among higher educational institutes in this pandemic situation.
\end{abstract}

The primary goal of this study is to develop a Virtual Learning Environment (VLE) for Advanced Technological Institute during the COVID -19 Pandemic, as well as to identify the existing virtual learning environment status of other higher educational institutes and implement innovative tools in Virtual Learning Environment (VLE) at Advanced Technological Institute in the COVID -19 Pandemic.

The conduct of this study involved qualitative method, the finding of the research presented that existing system used only for downloading the notes of lectures. As per the finding, virtual system developed using the following features such as conducing online examination, quizzes, discussion forum and as a new components automatic question generation using natural language processing added to enhance the learning and teaching process. Adobe photoshop for image editing purpose, MySQL for creating database, Apache Web Server, WordPress, Natural Language processing (NLP) for prototype question generation and php for virtual environment development as well as Microsoft Visio for diagram drawing were utilized to develop this system development.

Keywords: Virtual Learning Environment, Information Technology, Teaching and Learning Environment, Natural Language processing.

\section{INTRODUCTION}

The utilization of Information and Communication Technology (ICT) is a critical requirement for the creation of an expertise economy, especially in developing countries, in this pandemic situation. In the event of a Covid-19 pandemic, Higher education institutions are facing paradigm changes as they better utilize information and communication technology. As a result, virtual learning environments, which have increased in importance as a vehicle for knowledge transfer in both the academic and corporate sectors, are being used and implemented. Virtual education environment has grown in this pandemic situation quickly in importance for institutions and has been largely facilitated through the virtual learning environment (VLE) systems.

In every Society Innovative education have enormous obligations regarding building up the nation. The relationship between higher educational institute, government and market, experts and students have shown their commitment to the change of society and the whole world economy Virtual Learning Environment (VLE) plays an important role in this pandemic situation to enlightening the quality of education to accomplish required performance by offering numerous advantages for education, for example, giving ease framework, flexibility, scalability, coordinated effort, and convenience. Besides, it enables access it on-request from anyplace by means of the web.

This research looks on the use of a Virtual Learning Environment (VLE) at advanced technological institute during the COVID-19 Pandemic.

The goal of the virtual learning environment is to create learning solutions that allow for more flexibility in accessing learning resources and a wider spectrum of learners. As a supplement to face-to-face sessions, academic professionals can deliver knowledge and instruction to students via virtual learning. Virtual learning can also help higher education institutions save money and improve their commercial competitiveness. In the learning and teaching process, virtual learning is an arrangement of information technology and communication applications. Virtual learning environments 
are becoming increasingly important in the delivery of education. [1]

Rather than technology concerns, virtual learning failure is typically caused by academic staff and higher educational institutions' incapacity to provide learning process design and a lack of attention to non-technical domains.[2].

When it comes to virtual learning, higher education institutions don't merely use technology and upload learning content. Higher education institutions, too, necessitate thorough and fundamental planning. [3].

Virtual learning systems are used by certain higher education and technical training institutions to support distance learning (pure virtual learning), while others use them to enhance more traditional teaching methods. E-learning technology can be utilized to build a completely virtual learning environment for distance learning.

The utilization of the VLE has become a requirement at higher educational institutes in this pandemic situation. majority of higher education institutions have created their own virtual learning environment (VLE) for use by their own instructors and students. The success of a VLE, on the other hand, is wholly dependent on the happiness of its users. Thus, although there is an increasing sum of institutions who are very passionate about implementing VLE, there are still a large number of mainstream faculties who seem hesitant or reluctant to implement VLE for their teaching tasks. Furthermore, while the use of VLE is maintained by students and instructors, its implementation is launched and encouraged by lecturers' acceptance and use, which in turn begins and encourages students' use of VLE in classrooms. The success of VLE implementation centers on students' continued acceptance and use of the system.

In addition, assessing the performance of the virtual learning system's implementation is critical to its continued usage in the COVID-19 pandemic situation. It seems that knowledge available in the above context in Sri Lanka during Pandemic is also lacking. therefore, a need to identify the implementation patterns of VLE and influences in respect of Sri Lankan Higher educational institutes. This research is intended to evaluate the effective implementation of VLE as an additional tool in learning and teaching at higher educational institutes. Thus, it investigates about VLE tools and implementation patterns, Critical Success Factors for active implementation of VLE, evaluating the outcomes and providing set of recommendations in order to improve teaching and learning through VLE from different perspectives during the pandemic situation.

\section{Research questions}

The goal of this study is to obtain answers to the following research questions.

a. How is the status (usage and extend of use) of
Virtual Learning Environment (VLE) During the COVID -19 Pandemic in blended learning at Higher educational institute level?

b. Do lectures' performance have significant effect on students' Virtual Learning Environment (VLE) During the COVID -19 Pandemic?

c. Do students' perspective have significant effect on their Virtual Learning Environment (VLE) implementation?

d. Do VLE' characteristics have significant effect on students' VLE implementation?

e. What are the critical success factors or determinants of VLE implementationin blended learning at Higher educational institutelevel?

f. What are the possible actions that could be taken to develop virtual learning environment during the pandemic situation for Advanced Technological institute?

g. What are the innovative tools available in VLE during pandemic situation?

\section{Research objectives}

\section{Main objective}

The primary goal of this proposed research is to develop a Virtual Learning Environment (VLE) for Advanced Technological Institute to use during the COVID-19 Pandemic in order to improve teaching and learning.

\section{Sub objectives}

It is necessary to follow the following sub objectives in order to achieve the research's major purpose.

- To investigate the status of Virtual Learning Environment (VLE) During the COVID -19 Pandemic in blended learning at Higher educational institute level.

- During the COVID -19 Pandemic, assess the impact of lecturers' performance on students' Virtual Learning Environment (VLE).

- To investigate the effect of students' perspectives on their Virtual Learning Environment (VLE) During the COVID -19 Pandemic.

- To evaluate the crucial success factor of the Virtual Learning Environment (VLE) in blended learning at the higher educational level during the COVID-19 Pandemic.

- To develop and implement a suitable virtual learning system for Advanced Technological institute to enhance the teaching and learning practice during pandemic situation.

- To develop innovative VLE Tools to enhance the teaching and learning during pandemic situations. 


\section{LITERATURE REVIEW}

In a pandemic situation, the effective application of a technology is a multifaceted issue that can be influenced by a variety of nontechnical and technical factors. Several measures have been used in the works to evaluate technology installation. The determinants of effective technology implementations have been studied using a variety of paradigms.

From the perspective of students, this study categorizes important variables for effective implementation of a virtual learning environment in a pandemic situation in blended teaching and learning at Advanced Technological Institute. As a result, this research evaluates student perspectives (attitudes toward VLE, computer anti-anxiety, self-efficacy, experience, and interaction with other students and lecturers), lecturers' performance, VLE characteristics (service quality, information quality, and system quality), and organizational characteristics (Higher Educational Institute support).

This era's key focus is the assessment and application of Virtual Learning Environment (VLE) in higher educational institutions during the COVID-19 Pandemic. Anyone that has access to educational services, such as lecturers, teachers, scholars, and staff members, is referred to as a stakeholder of a higher educational institution.

A virtual learning environment (VLE) is an online platform for providing students with high-quality training and materials, as well as keeping them informed on conformance and skill development. An organization must prepare and plan before adopting and implementing a VLE.

Mahoney etal.[4] have determined that external electronic educational resources must be consolidated, internal electronic educational resources must be hosted, and new online learning materials must be created. The authors used 12 interviews to evaluate the features of four VLEs and uncovered a costeffective curriculum management solution that has all of the capabilities needed to support existing teaching methods.

NurakunKyzy et al.[5] The preferences and attitudes of VLE users were investigated, and it was determined that four factors influenced students' impressions of VLE: technical features of VLE ease of use, VLE feedback options, and VLE benefits of use.

Another study Little [6]VLE implementation could bring practical benefits to the firm, such as improved productivity and business goals, according to the discussion. Support and service, unique selling proposition, user interface, features, unique, modernizing speed, adaptability, and consumer feedback are all things to think about. Only a small portion of the selection was revealed.

Whereas a study by Park and Jo [7] Researchers used activity theory to evaluate the activation levels and usage patterns of VLE utilizing online activity data from 7940 courses, resulting in distinct activity patterns within different courses colleges as well as restricted use of virtual campus with small modifications.

Walker et al.[8] first, identifying VLE features that will promote teaching and online learning, second, the impact of VLE quality on meeting instructor needs. Walker et al.[8] assessment tools, grade book, interface, course materials, communication tools, class student, and administration participation were discovered to have both good and negative attitudes. Walker et al.[8] Positive views regarding VLE attributes confirmed VLE selection, whilst negative attitudes focus on future threats that must be addressed for VLE implementation.

Additionally, Sriprasertpap[9] The purpose was to establish an online training platform for students and teachers to use for collaborative learning in the traditional classroom and on-thejob training. Sriprasertpap[9] created a five-part online training paradigm that includes creativity, a virtual learning environment, instructional material, interaction, and evaluation. The author demonstrated that in usability testing, two-way communication through virtual learning and evaluation is critical, and teacher-student participation is encouraged.

Malganova et al. (2016) prove that the Moodle LMS was well-liked by hundreds of students all throughout the world. Universities that had previously used the Web and Blackboard systems migrated effortlessly to Moodle, which was nearly complete and, in comparison to its competitors, operated on a non-commercial basis. Universities can fully localize their sites in 43 different languages using Moodle's plugin packages. On the basis of interactivity, flexibility, collaboration, and motivation, embrace Moodle with open arms. Some of the advantages that Moodle has over its rivals include the fact that it is open-source and can combine the development, reviewing, and amending of training materials by the teacher and adult learners at Tier 1 and 2 colleges such as Stanford University and Texas A\&M University.

Students may also collaborate collaboratively to create collaborations using web-based interactive learning resources. Web-based interactive learning is a type of education that connects educational foundations teacher, students, and resources via internet information and communication technology. [10]

Teachers and students can benefit from a Virtual Learning Environment (VLE). The Learning Management System (LMS) is a platform that allows instructors and course designers to manage the distribution and delivery of learning resources assignment and course materials, in these LMS, discussion boards and online forums have become valuable resources. These platforms allow professor and student to communicate online, allowing them to mix and study together. [11]. 
A web based VLE is proposed by HamsiahMohdDahalan and Raja Maznah Raja Hussain [12] The system was built utilizing the open source platform Moodle to aid in the evaluation of learning and teaching.

Having discussed the previous literature it was found that there is no research related Virtual Learning Environment (VLE) During the COVID -19 Pandemic at advanced technological institute and also there is a dearth of research in case of our Advanced Technological institute context. Therefore, researcher is interested to propose a Virtual Learning Environment (VLE) During the COVID -19 Pandemic with innovative novelty features tools for advanced technological institute.

Digital learning experiences are thought to provide additional learning benefits that can help students and educators develop their skills. The almost widespread approach to the implementation of virtual learning at Higher educational institutes has been the implementation of an VLE such as Blackboard, Moodle or Sakai, Angel etc.

VLEs enable institutions to change and develop new educational techniques while also allowing them to be more flexible. Higher educational institutions have built their own VLE portal for their own students' use. In a blended and online learning environment, VLEs are also one of the options that are beneficial to both students and instructors. VLEs are online learning environments that allow students and lecturers to communicate and engage.

Lecturers may be able to use the VLE to integrate instructional materials as well as interactive capabilities like discussions, file sharing, and forums. VLEs also help with management responsibilities including distribution and monitoring, exams, preparation, interactive live lectures, and numerous statistical assessments. Lecturers will save time and effort by using interactive teaching techniques.

This study takes a closer look into VLE tools, VLE implementation patterns, critical success factors or determinants of VLE implementation, assessing the outcomes and providing set of recommendations with the effort to increase the VLE's implementation into learning and teaching in order to confirm the success and enjoy the benefits of VLE.

\section{Background of VLE}

During the Covid-19 outbreak, the usage of VLE in learning and teaching has gradually grown in higher education. Virtual Learning was thought to be the new vehicle that would bring education to new learning approaches because it supplied electronic learning resources to far away learners.

The COVID-19 pandemic has had a variety of effects on education, particularly teacher education. Due to the closing of colleges and classrooms, educators and students had to quickly learn how to educate from a distance. There is no exception when it comes to teacher education. The requirement for students to be able to train in simulated worlds. In order to fulfill not only the needs of students but also the standards of teaching, educators must make decisions, choices, and modifications as part of their teacher education training. [13].

The VLE is a group of information technology tools used by higher educational institutes, and students to enhance their teaching and learning experience. The VLE can be used to enhance traditional classes or as the principal mode of communication for online courses. The VLE is comprised of course management software and other collaborative applications. Information Technology supports, maintains, and develops these software platforms. Higher educational Instructional support and training are to be provided for the effective implementation of this Virtual learning environment during the pandemic situation.

\section{Prior Studies of e-learning Assessment}

In larger programming classes, there's also the question of pupils' access to computer resources, which can make assessment methods quite difficult. In authentic and constructively aligned programming assessment, Students should be able to write programs in the same environment as they would in the real world: on a computer with rapid feedback from the programming community, trail-and-error or debugging approaches, iterative submissions, and the generation of practical programs. On the other hand, traditional written exams are used to evaluate many programming courses. [14].

Written examinations can have a major logistical drawback in that grading them is a time-consuming and difficult process. Scoring a traditional written programming exam for a 400 student class could take up to 40 hours, according to the authors. Task definitions, procedures, and labeling scripts, as well as grading, access limits, scheduling settings, similarity tests, and how a pupil's code is performed on the secure server, are all handled by the Moodle registry. The plug-main in's module allows many jail servers to be used in a single Moodle system. When a student submits a program for execution, the instructor's execution scripts are likewise sent to the prison server. The appropriate parser or interpreter is then used to run the code utilizing these scripts. The output of the program, compiler, or interpreter is delivered to the learner via a standard command-line interface.[15]. VPL provides graphical output from programs in addition to the command line interface. The VNC remote access program, which comes pre-installed on most recent Linux distributions, is used to accomplish this. This interface then returns to the student's browser a basic Windows environment, allowing them to engage with the environment's graphical capabilities. 


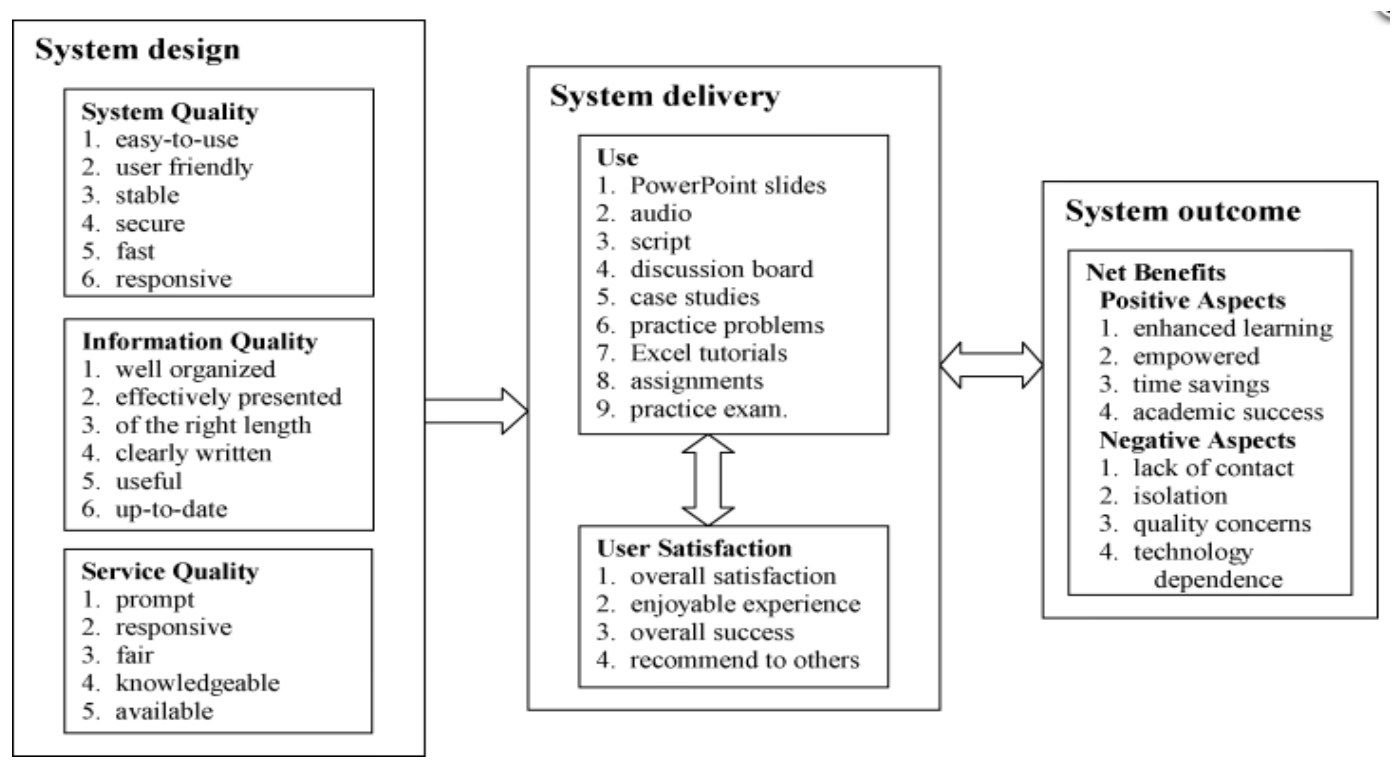

Figure 1: The E-Learning Success Model and Sample

In system design, components of e-learning success models are evaluated from three dimensions. The first dimension is system quality, which measures the suitability of the "such as speed, security, ease of use, stability, and ease of response. The second measurement relates to information quality and focuses on evaluating the course content (usefulness, length, presentation, organization, and prevalence). The third and final measurement is related to the e-learning service's consistency, and it assesses student-instructor interactions using words like promote, equal, attentive, and knowledgeable. Two success dimensions are used to measure the system's delivery. The first is usage, which assesses the instruments used, such as audio recordings, PowerPoint slides, and lecture notes. The Positive aspects include enhancing learning and time saving, while the negative aspects include concerns regarding quality and a lack of content. All components of the success assessment are linked and the success of any of these components can influence another component. As a result, it's critical to pay great attention to every component. [16].

The system quality dimension assesses the e-learning environment's desirable characteristics, such as usability, user friendliness, stability, protection, speed, and responsiveness. Course content is evaluated in terms of structure, presentation, duration, utility, and currency on the knowledge quality dimension. The promptness, responsiveness, fairness, competency, and availability of student-instructor interactions are evaluated by the service quality factor. The usage dimension assesses how often the course components are currently used, such as the number of times they are used. The user satisfaction factor assesses students' feelings about elearning based on their course experience. Satisfaction, happiness, performance, and recommend ability are all factors considered. The positive and negative features of e-learning, such as empowerment, time saving learning enhancement, and academic achievement, are all included in the net benefits dimension.

This model also considers how technological features of an elearning system affect its effectiveness. In pandemic scenarios, little research has been done on the perspectives of instructors and students on virtual learning environments Despite its widespread use, the researchers wanted to investigate how instructors and students felt about using elearning. Furthermore, self-paced, teacher-led, and immersive education are key determinants in learners' opinions regarding virtual learning as an effective learning approach. Virtual learning's perceived utility and self-efficacy in a pandemic scenario influence behavioral desire to use it. This study presents a guiding principle for creating virtual learning environments in pandemic situations based on the findings.

\section{Prior Studies of VLE Usage Assessments}

Another issue that has gotten a lot of attention in VLE-using institutions is determining how to assess how much staff and students use the VLE. Despite the shift toward more studentcentric learning aids, research has revealed that the primary driver of VLE use is still the teaching staff. When the challenge of knowing the amount to which a VLE is currently used inside an organization is considered, the necessity for a credible guide to the extent of VLE use becomes obvious.

Janossy, J.[17]proposed the development and proposal outlined in depth was guided by the development of an evaluation method that allows for comparison of use among elements of a college and among colleges Figure 2 depicts a model for the source of a simple metric expressed as a number between 0 and 13 . 


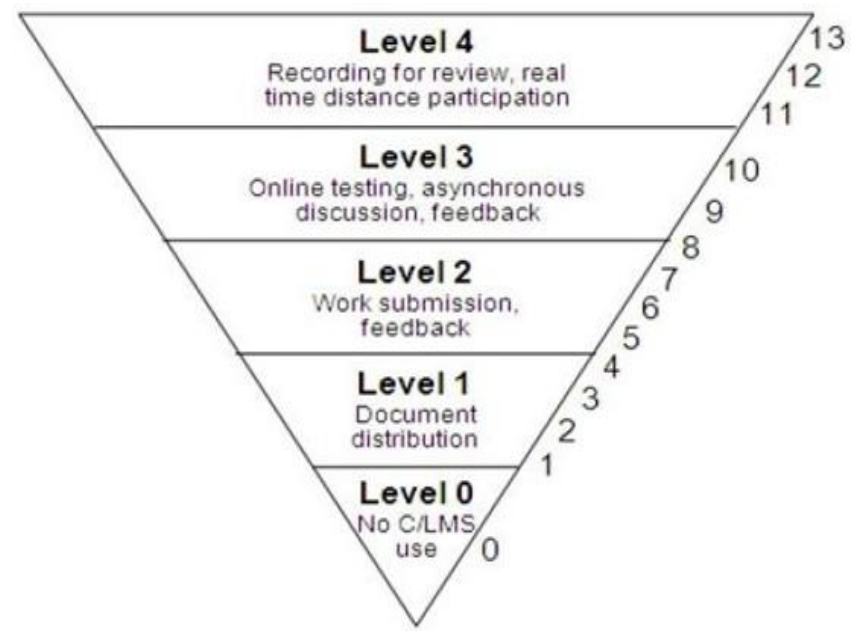

Figure 2Janossy's VLE Usage Level and Metric Values

This model was created based on the notion of five general "levels" of expected C/VLE usage These five levels range from a lack of usage of the C/VLE by an instructor to a level that exceeds the capabilities of most C/VLE systems using technology now available to many schools. From the lowest to the greatest metric value, Figure 2 offers further information on the efficient use indicated by each metric value:

Level 0: When an instructor does not create a course in the VLE or does not allow students in the course to access the VLE, level 0 happens.
Level 1: refers to instructors uploading lesson content and students downloading lesson content or completing assignments using the virtual learning framework in a very simple way in a virtual learning environment, Level 2 refers to the employment of a communication tool.

Level 3: The use of a testing tool is referred to as Level 3 testing (survey, pool or quizzes). Students can, for example, take online receive immediate feedback, quizzes and exams such as "feedback" responses for incorrect answers and the like.

Level 4: is obvious in light of recent technical advancements that necessitate information sharing and treating operators as co-developers. This is currently handled by including a blog module in the framework, but additional modules will be introduced in the future to make VLE use even easier.

\section{Research Model}

The research design phase is critical for surveying the relevant circumstance. The objective of the study, research model, nature of the data, and other study backgrounds, among other factors, influenced the research design and choice of research design. Analysis and problem description, prototype system design and implementation, prototype system upgrades, and advanced query implementation are the three phases of this study. Figure 4 below illustrates the research model that was used to meet the objectives in each phase:

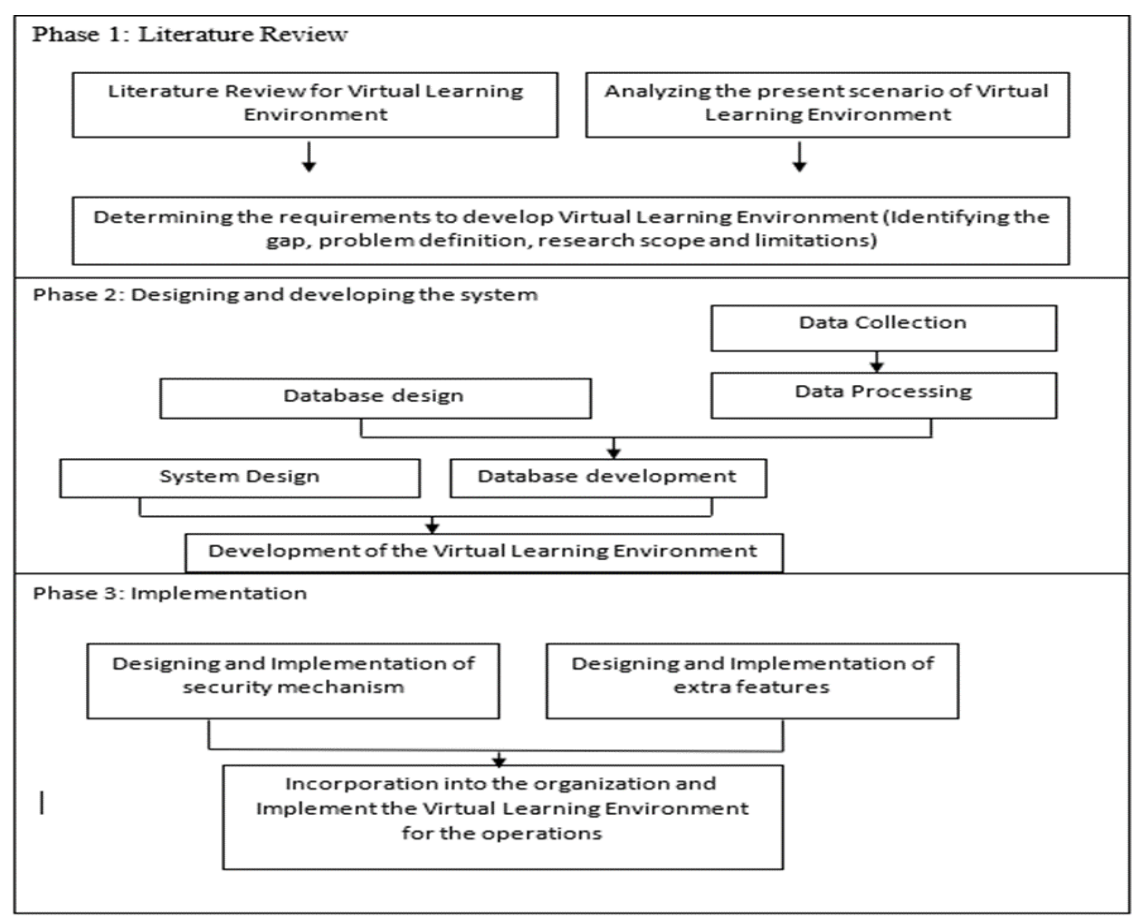

Figure 3 Research Methodology 


\section{Phase 1}

The first phase of the project begins with a survey of the literature on Virtual Learning Environment (VLE) During the COVID -19 Pandemic. Following that, the literature study focuses on virtual learning environment technologies and their use in virtual learning and management strategies. The need for a virtual learning environment in a pandemic condition is recognized based on a preliminary literature review. The system architecture and how it works are thoroughly examined in order to comprehend the current virtual learning environment scenario.

Phase 2

In this phase Data collection starts with various Higher educational institutes. Formal interview method was used to collect data with structured questions. Secondary data were gained from research papers, websites, newspaper and book articles associated to virtual learning environment applies in Higher educational institutes in Sri Lankan context. Data was collected, evaluated, and the virtual learning environment requirement for Advanced Technological Institutes in a pandemic condition was found.

\section{Phase 3}

This phase is mainly concerned with system implementation, which entails the development of a new system and its deployment into production. Security features and additional functions will be added further and finally the system will be implemented to the real world.

Furthermore, the figure 5 depicts the overall system development has been elaborated as a use case diagram. Based on the preliminary studies few major activities have been identified and few stakeholders have been added into the system development. In any event, based on the literature review and data collection, this use case diagram can be modified.

The basic research model used in this study to examine the concepts and their relationships in comprehending the VLE implementation in Advanced Technological Institute during a pandemic condition is depicted in Figure 4.

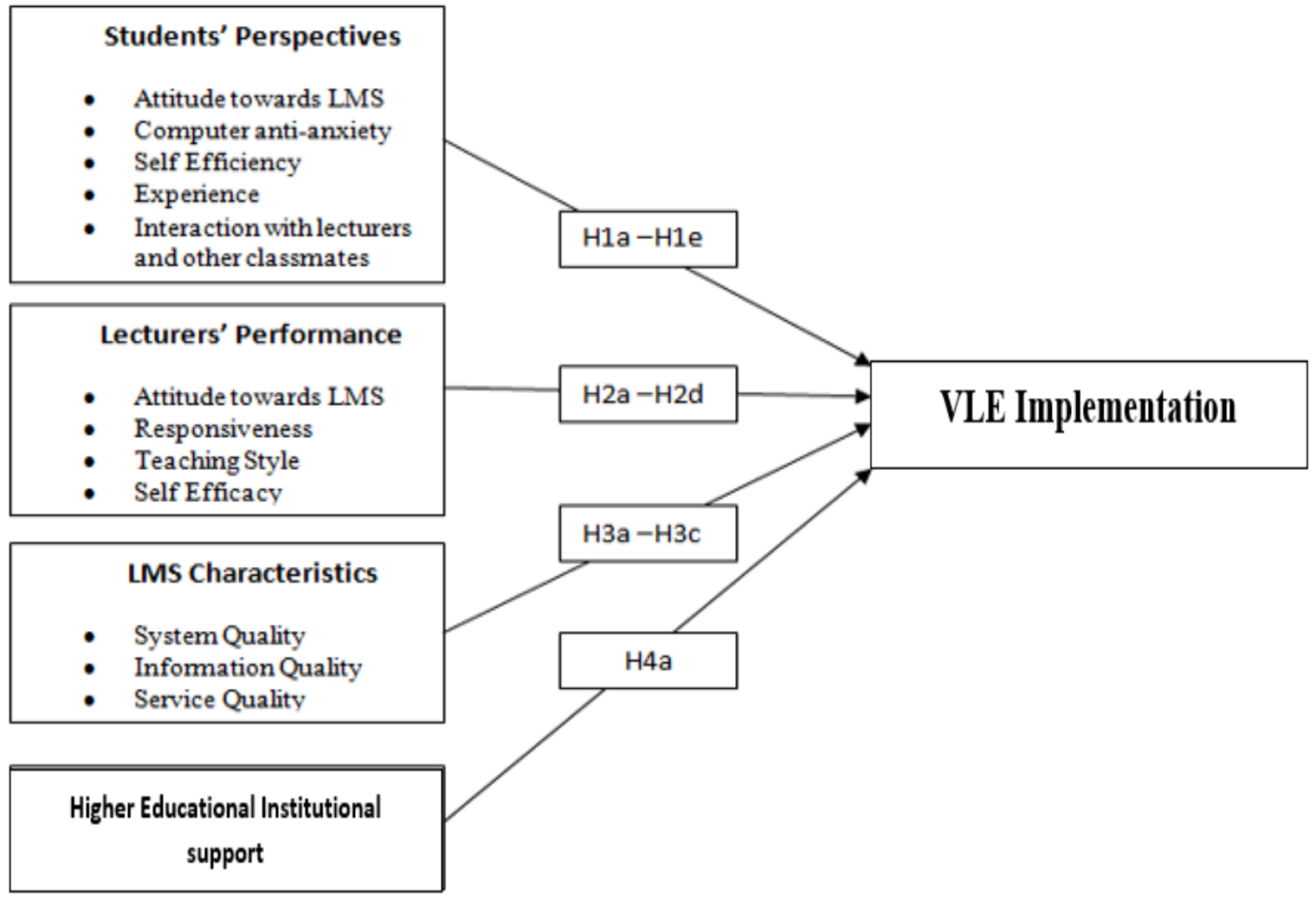

Figure 4 Elaborated Research Model

Proposed Use Case Diagram for Virtual Learning Environment (VLE) During the COVID -19 Pandemic for Advanced Technological Institute 


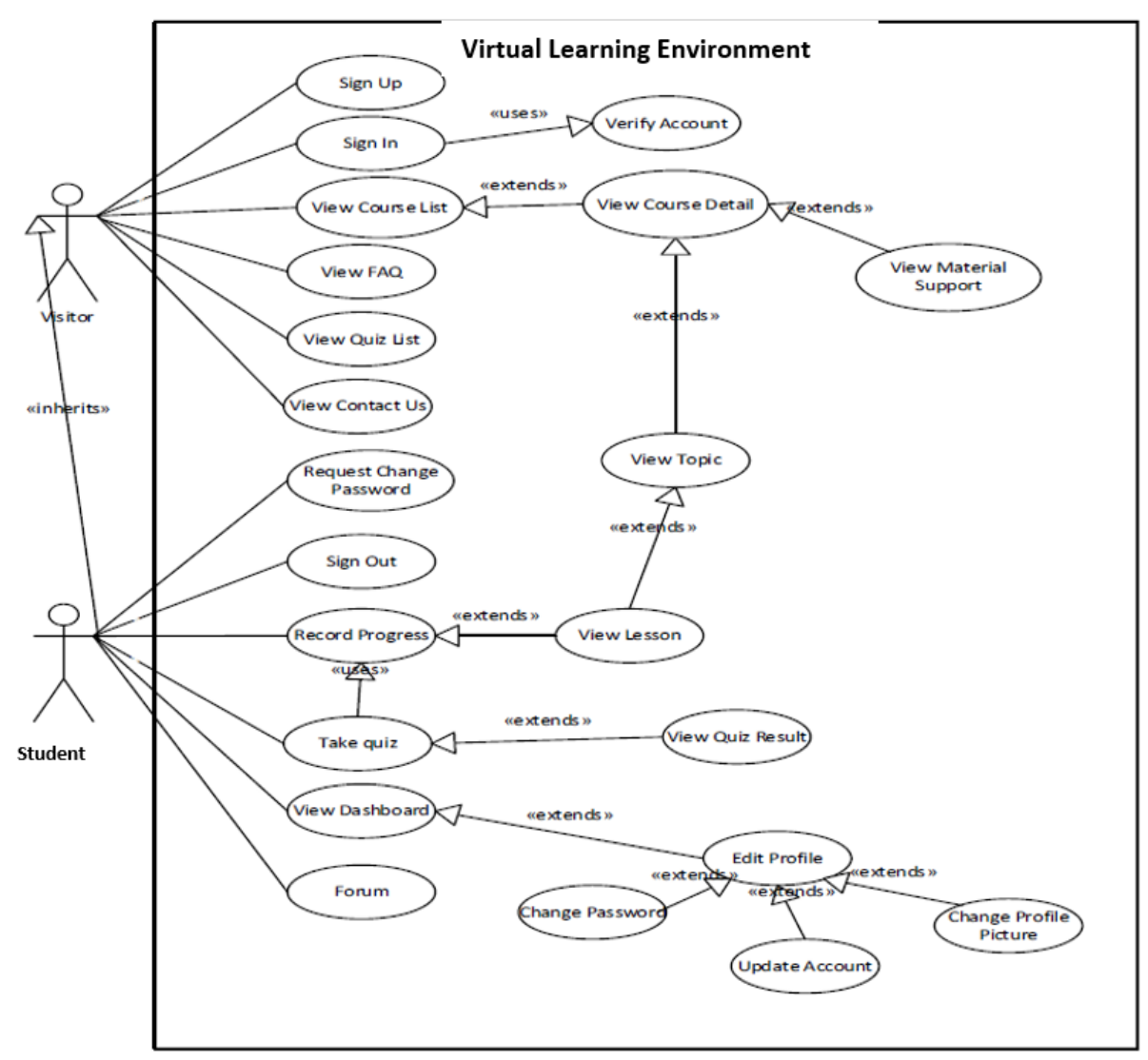

Figure 5:overall system development has been elaborated as a use case diagram

\section{RESEARCH METHOD}

A qualitative study was conducted in order to meet the research's aims. Qualitative research is distinguished by the fact that its effects are not observable or quantitative, and it is best suited to small groups. Its primary benefit, as well as its primary distinction from quantitative research, is that it gives a comprehensive examination and discussion of a research topic without restricting the scope or purpose of the study participants' comments.

Although qualitative research is best suited to small groups, there is a risk that the findings will be interpreted as representing the opinions of a larger group of people. However, qualitative research's usefulness is strongly dependent on the researchers' talents and abilities, and the results may not be perceived as reliable because they are largely based on the researcher's own personal judgments and interpretations.

\section{IV.THE POPULATION AND SAMPLE}

\section{Population}

Major stakeholders involved in the Virtual Learning environment for Advanced Technological institutes have been considered as a part of the study. The stakeholders involved in the generation of virtual leaning environment were found to be Students, Lecturers, Demonstrators, and higher educational institutions etc.

\section{Sample and Sample Size}

This study was developed using a purposive sampling strategy. This strategy, which is classified as non-probability sampling, involves selecting sample members based on their relationship to, experience with, and comprehension of a research issue. Because of the expense, time constraints, and population size, the sample size is limited.

\section{Data Collection Methods}

The interview technique was employed for the determinations of this learning. Participants' emotions, sentiments, and opinions on the study issue are elicited through personal and structured interviews. Personal interviews offer the advantage of involving personal and direct connection between interviewers and respondents, which eliminates non-response rates; nevertheless, interviewers must have developed the necessary skills to conduct a good interview.

During the investigation, the researcher used a semi-structured questionnaire as an interview guide. In terms of data collection equipment, the researcher prepared a set of questions to guide the interview toward the study's goals, but more questions arose during the interviews. 


\section{Research Process}

A meeting with academics and students from Higher Educational Institutes was held in November of 2020 in order to gain acceptance for their participation in the research. More exactly, after explaining the study's goal and scope, the researcher contacted them and encouraged them to join. The interviewers conducted the interviews between November and December 2020, and the respondents were typically enthusiastic to engage in the study. The discussions lasted approximately 20 to 25 minutes. Participants took notes during the interviews to assist the researcher in assessing the information gathered.

Respondents were permitted to express their ideas on any topic they desired during the interview, even if it wasn't addressed in the discussion areas or listed in the data collection methodology. Finally, it should be mentioned that the discussions went easily and were enjoyable.

\section{Data Analysis}

Data from personal interviews was analyzed using content analysis. According to Moore \& McCabe, Data is categorized into topics and sub-themes for this type of research so that it may be compared. One of the most significant benefits of content analysis is that it aids in the reduction and simplification of data while still delivering reliable results.

\section{System Development}

Automatic question generation added as a novelty of this research. following section describe the process flow.

\section{Flow Chart for Question Generation}

Automatic question generation component added as a novelty of this research. flow chart for question generation clearly illustrate this. (1) Preprocessing, (2) complicated phrases are broken down into smaller chunks, (3) post-processing, (4) putting sentences together (5) semantic role labeling or dependency parsing and (6) generation of questions are all steps in the question generating process. The generating of questions returns a question.[18]

The proposed solution selects the pair with the best statistical strength. Use technologies for dependency parsing and semantic role labeling to identify critical characteristics of speech as subject, objects, roles, action, location, time and so on. first, before extracting and processing useful facts from user comments, normalize inputs for capitalization and punctuation[19]. Use POS tagging, dependency parsing, noun stemming, and semantic role labeling to extract specific parts of user responses, such as nouns, verbs, subject, place, object, time, action, and person information. This allows us to turn a statement into a question and locate the most meaningful sections of multi-word inputs for the user (proper names of people, nouns, and locations, verbs, or adjectives). The whole question generating flow chart is shown in Figure 3.

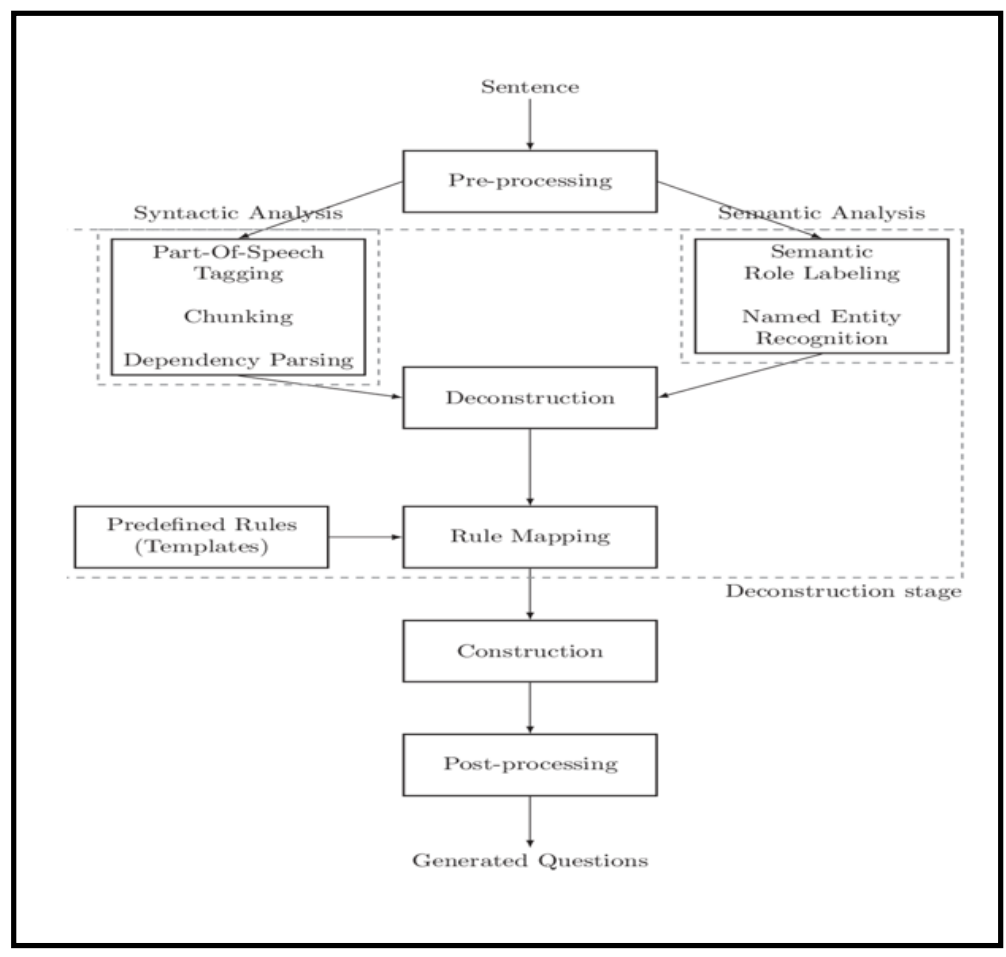

Figure 6 : Question Generation Flow Chart 
Flow Diagram for Automatic Question Generation

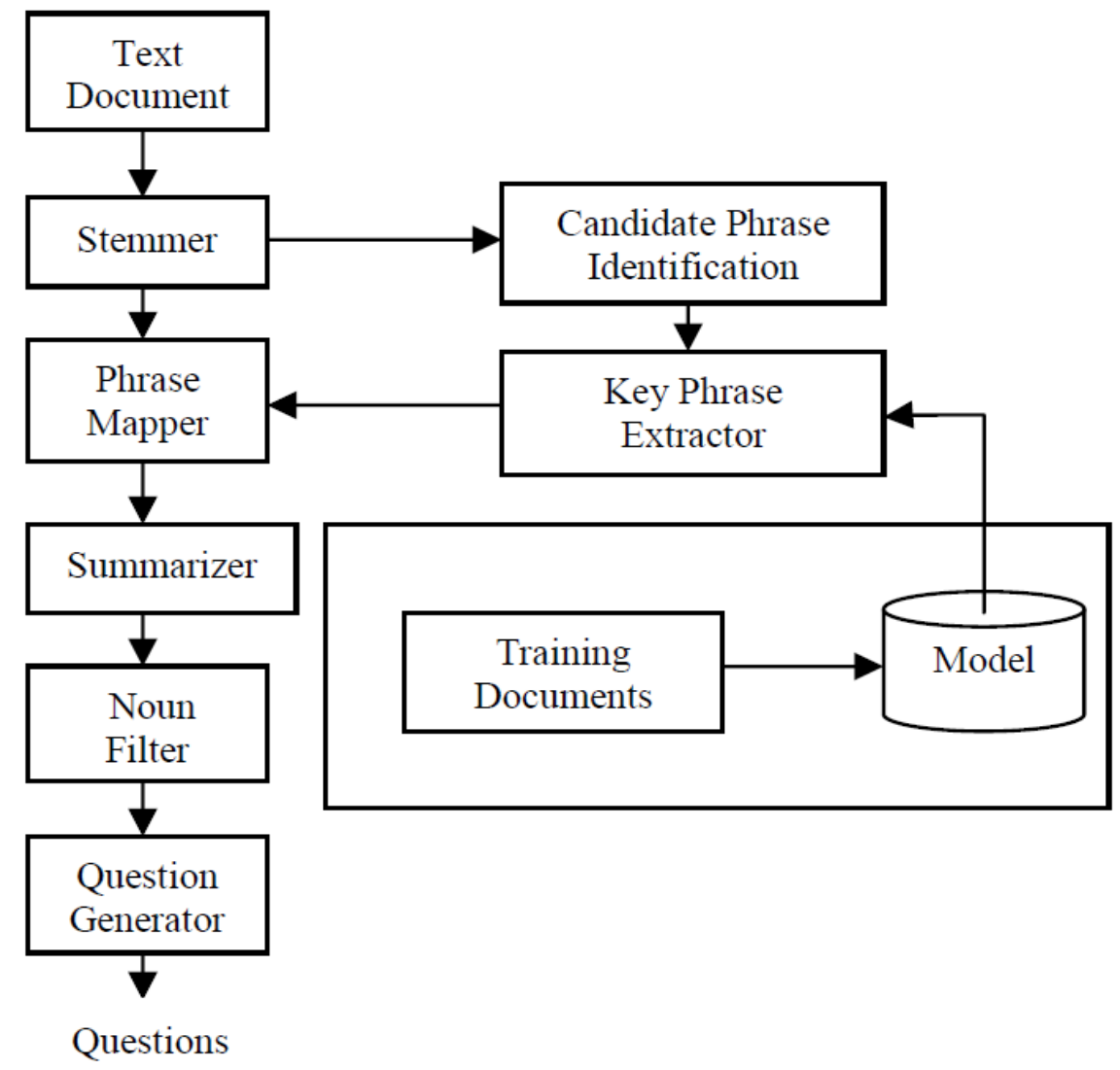

Figure 7: Flow Diagram for Automatic Question Generation

\section{Stemming}

Stemming is done to reduce misinterpretation during key phrase extraction. The Porter stemmer rules are used to do this. There will be no duplicate of essential keywords extracted.[20]

\section{Key phrase Extractor}

The important phrase is the key phrase is extracted from the stemmed file by the extractor. To draw important phrases, a supervised Naive Bayes technique is used. Key phrases are extracted from the text using the key phrase extraction procedure. In this procedure, the key word extractor is trained using the training data.[21]

\section{Phrase Mapper}

The Phrase Mapper makes use of the key phrases extracted by the key phrase Extractor. Each key word corresponds to a database file. The database is queried for the file name that matches the name of the key phrase.[22]

Automatic Question Generation using NLP

Installation and mount Google Drive

\section{Summarizer}

Summarization is the process of compressing the contents of a text in order to acquire clear and concise information from the source. The purpose of summarizing should be to extract only the required sentences from the text while deleting the unnecessary information the document's most crucial points should not be overlooked. Single-document and multidocument summaries are both possible.[23]

\section{Noun Filter}

The summary document is used to filter the document's nouns. Nouns include people, possessions places, things, animals, and ideas. The main element of a sentence is the noun, which is used to generate questions.[24]

\section{Question Generation}

Based on the Questions generation rules, the summary document is used to generate questions, which are filtered for nouns.[25] 


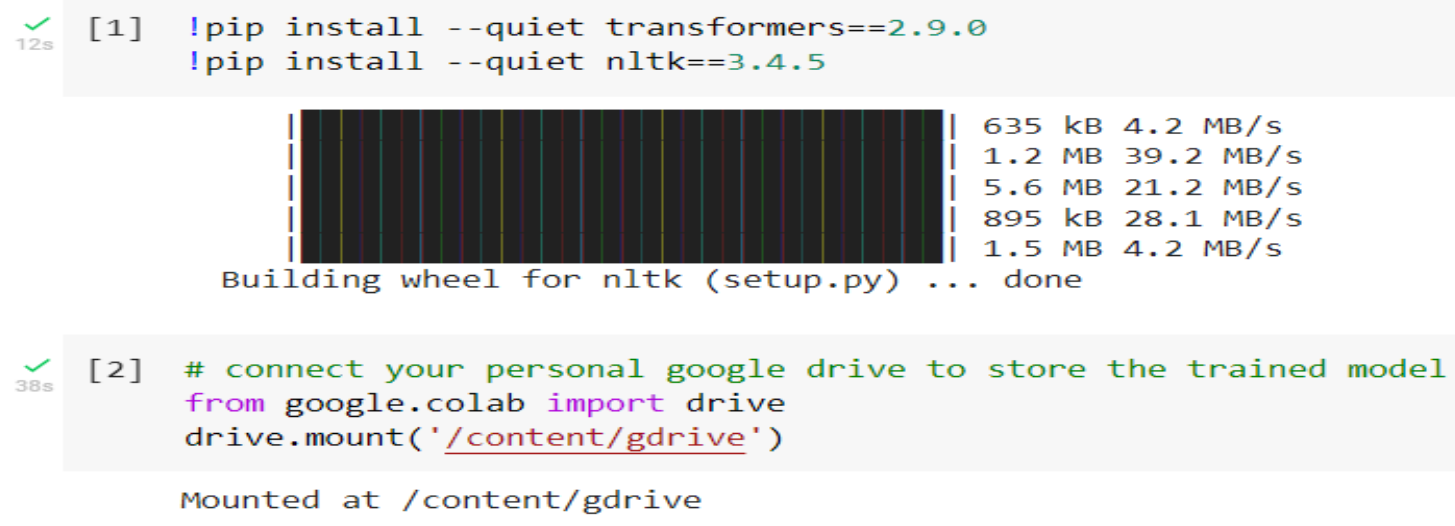

Figure 8: Mount google Drive

\section{Generate distractors (wrong choices) for MCQ options}

[3] import nltk

nltk. download( 'wordnet')

from nltk.corpus import wordnet as wn

sentence1 = "Srivatsan loves to watch cricket during his free time"

sentence 2 = "Srivatsan is annoyed by a cricket in his room"

[nltk_data] Downloading package wordnet to /root/nltk_data...

[nltk_data] Unzipping corpora/wordnet.zip.

[4] \# An example of a word with two different senses

original_word $=$ "cricket"

syns $=$ wn. synsets $\left(\right.$ original_word, ' $n^{\prime}$ )

for syn in syns:

print (syn, ": ",syn.definition(),"\n")

Synset('cricket.n.01') : leaping insect; male makes chirping noises by rubbing the forewings together

Synset('cricket.n.02') : a game played with a ball and bat by two teams of 11 players; teams take turns trying to score runs

Figure 9: Create Distractors

\section{Pretrained BERT WSD Model and extract}

$[6]$

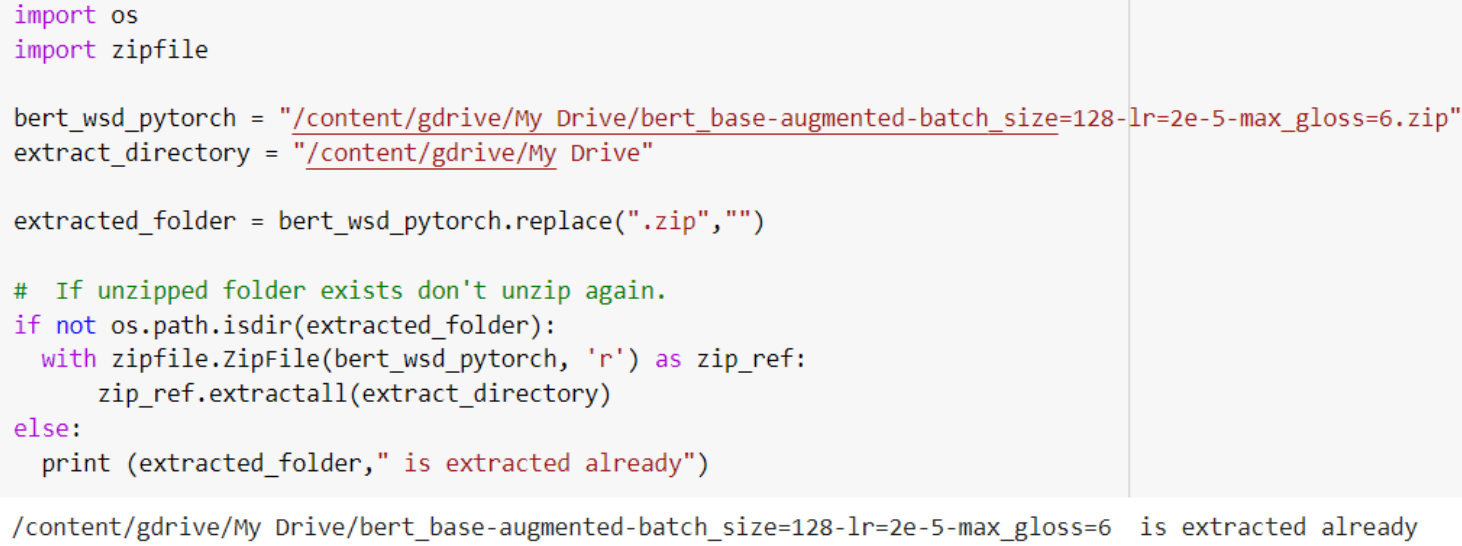

Figure 10: BERT WSD Model 
Create a question based on the context and respond with T5.

\section{Generate a question using T5 Transformer model}
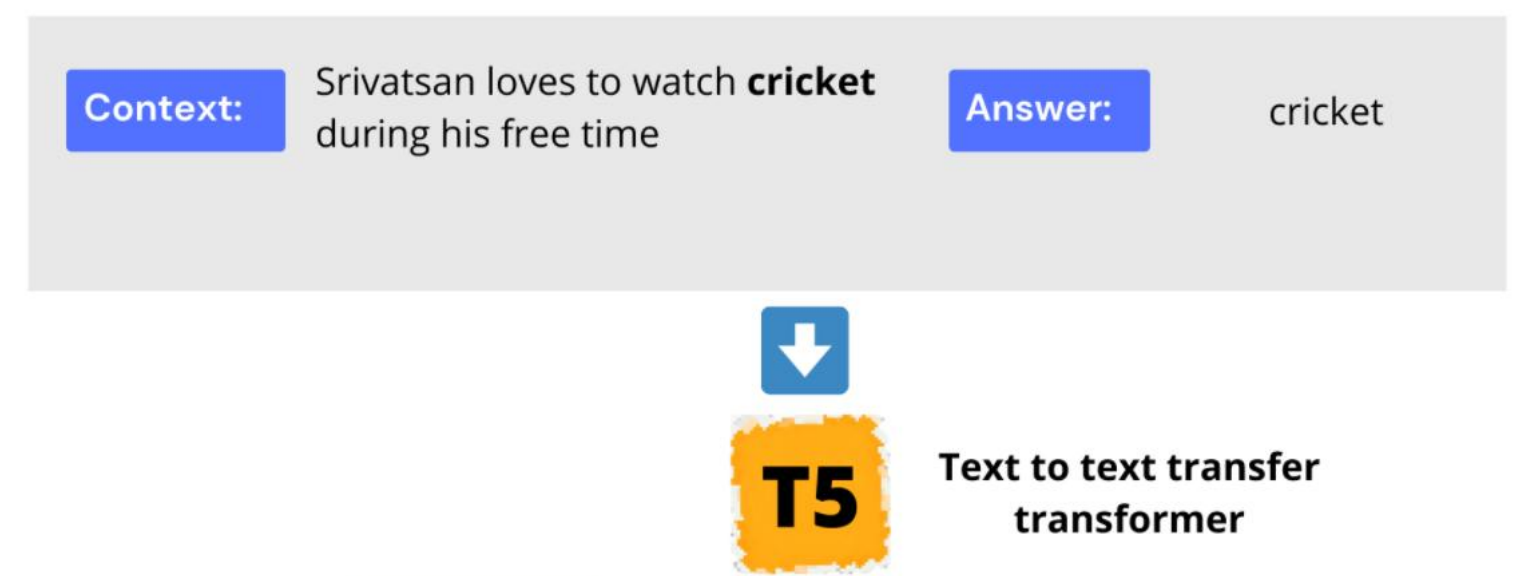

\section{Question What sport does Srivatsan enjoy watching?}

Figure 11: T5 Transformer Model

Question generating output the application of Natural Language Processing

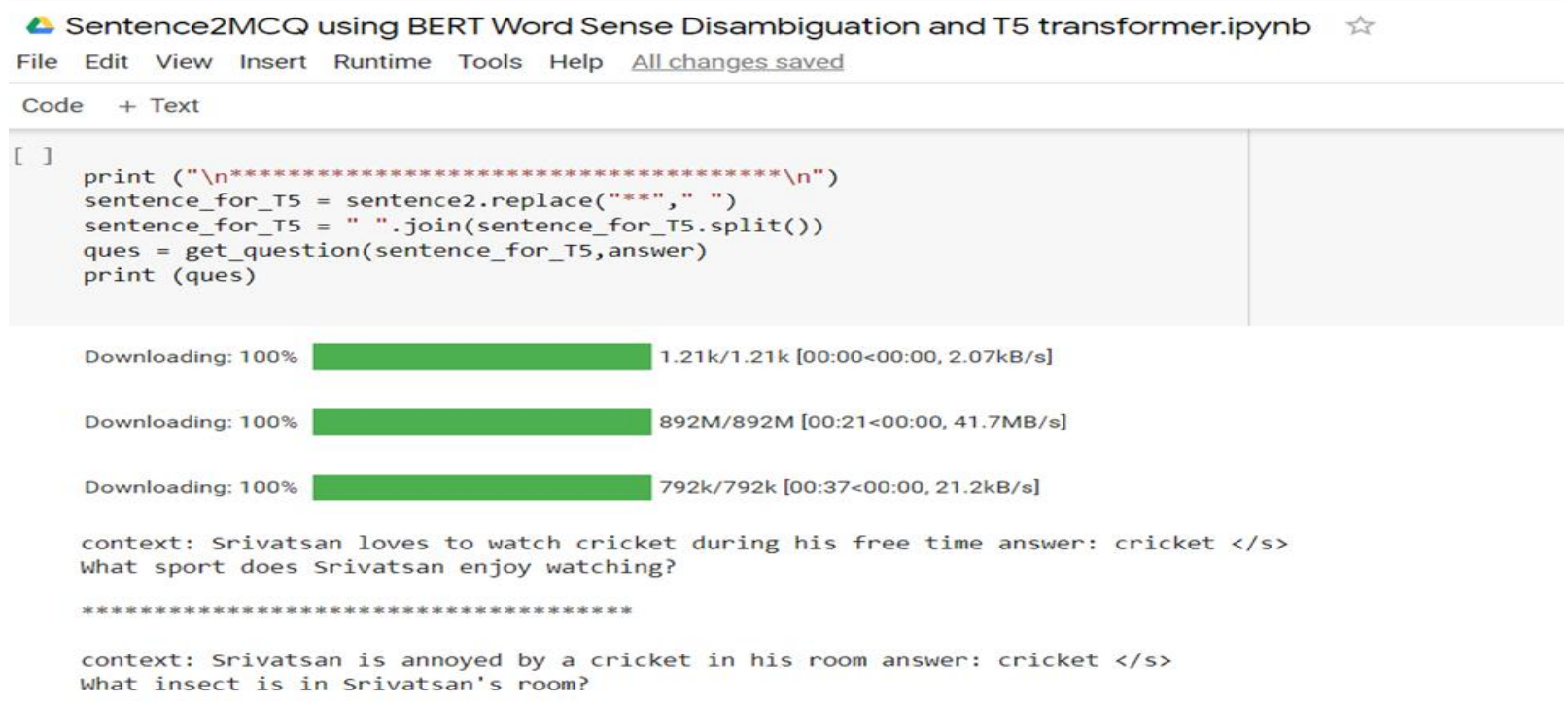

Figure 12: NLP question Generation Output

\section{CONCLUSION}

In conclusion, the main goal of this study was to explore and investigate the current status of virtual learning environments at Advanced Technological Institutes, as well as to study the problems that Advanced Technological Institutes face in implementing virtual learning environments in teaching and learning practice, and to implement a virtual learning environment with recommended additional features that can help to minimize the teaching and learning practices issues in this pandemic situation.Data on existing level of virtual learning practices, data on student's involvement processes, data on institutional support, data on and existing virtual learning environment practices in pandemic situation stratagems were composed. Secondary data was gathered 
from a variety of sources, including local websites, media stories, research papers, and book articles, all of which were relevant to the virtual learning environment during the pandemic scenario in both the global and Sri Lankan contexts.

According to the findings, conceptualization of students' VLE implementation consists of following VLE tools:i.e. downloading course content, chat, discussion forum, e-mail automatic question generations, and assessment. However, one VLE technology, namely downloading lesson content, was definitely utilized at Advanced Technological Institute based on the analyzed data. as a finding of this research automatic question generation tools added as a novelty of this research.

\section{The effect of students' perspectives on their VLE implementation}

It is difficult to know the status of students' characteristics as perceived by students' views in a VLE implementation environment, particularly in the context of an Advanced Technological Institute. Prior to the start of this study, characteristics such as students' attitudes toward self-efficacy, collaboration, VLE, computer anti-anxiety and experience with lecturers and other classmates, in particular, were unknown to that purpose, this section discusses the findings of the state of students' attitudes about VLE, selfefficacy, experience, computer anti-anxiety and contact with lecturers and other classmates. Students' perceptions on the above-mentioned features were found to be quite good and favorable, according to the findings of this study.

Students' attitudes are influenced by their desire to participate in virtual learning activities via computer use, therefore utilizing the VLE environment. Respondents stated that their attitude toward VLE is motivating and delightful, and that they are enthusiastic about building a VLE-friendly atmosphere. This is because almost all students believe that using the VLE will help them study more effectively in a variety of waysThis is in line with the concept of Technology. According to this paradigm, consumers' attitudes about technology and, as a result, their decision to utilize it are influenced by their opinions that a new application is beneficial and simple to use.

The VLE is not causing any problems for the pupils as a result, system quality features including an intuitive interface, navigation, access and structure, among others, put them at ease and encouraged them to use the VLE for their learning objectives.

All of the above-mentioned students' perspectives were hypothesized to be meaningfully related to VLE implementation. Subsequently, findings of the study further confirmed that all of the formulated hypotheses were fully supported According to these findings, students' attitudes toward VLE, engagement, collaboration computer anti- anxiety and self-efficacy, with lecturers and other classmates were all significant drivers of VLE implementation.

The effect of lecturers' performance on students' VLE implementation

This study does not fail to place a stronger concern in examining the effect of lecturers' performance on students' VLE implementation. In a pandemic situation, lecturers are the primary drivers of VLE. If educators are interested about virtual learning and have active and positive attitudes, students will be motivated to study more. The proposed social influence model of technology by Fulk, Schmitz, and Steinfield noted that the attitudes of those in the group or their superiors about technology has an impact on people's perceptions Individuals are supposed to observe others' actions, emotional reaction and behaviors in order to build their own coordinated patterns of conduct. Since one has been a student, one has been subjected to the performance of lecturers, and this performance is one of the factors that influences students' conduct. As a result, lecturers' performance was discovered to have a predictive effect on students' VLE implementation.

The lecturers' performance of this study comprised four variables or dimensions namely attitude towards VLE, responsiveness, teaching style, and self-efficacy remain unknown until undertaking this study. Results of this study have empirically presented that Lecturers' performance towards the above-mentioned characteristics were very delighting and satisfactory.

The ability of lecturers to respond to virtual learning is crucial to the VLE's success. The student's perception of a prompt response from the lecturer to online concerns and wants is referred to as lecturer responsiveness. Students may see the importance and success of using a VLE in blended learning because of the educators' rapid responses. As a result, trainers' quick virtual responses encourage students to use VLE and be satisfied with it. This study indicated that lecturers' response has a considerable impact on students' VLE adoption, which is in line with the researcher's expectations.

From the learner's perspective, the lecturer's teaching style is critical to the success of the VLE. Students' participation and contribution, engagement, cognitive and attitudes toward technology are all positively influenced by teachers who use a collaborative teaching method. As a result, teachers that use an interactive approach to teaching encourage students to utilize, accept, and love the VLE. With regard to the teaching style, this study concluded that the teaching style had bearing only $8.8 \%$ of effect in determining students' VLE implementation. This is because some of the lecturers but not all encourage and motivate the students to use VLE and explain how to use the VLE components. 
This study also focused investigating the level of lecturers' self-efficacy from students' perspectives. This measure received the highest evaluations from respondents among the four lecturers' performance variables. Because students perceive that their lecturers are proficient with all the contents used in VLE, and it would result to students implementing the VLE. Hence, the study revealed that lecturers' self-efficacy has strong predictive power on students' VLE implementation.

All the four lecturers' performance of this study postulated that those to be significantly related to students' VLE implementation. As a result of the analysis, all of the assumptions about lecturers' performance and VLE implementation variables were found to be completely validated.

In conclusion, the findings and discussion offered in the preceding paragraphs have aided in answering one of the research questions and achieving one of the studies aims, namely, that lecturers' performance has a good impact and influence on students' VLE implementation.

\section{The effect of VLE characteristics on students' VLE implementation}

In the same way that there were no empirical reports on students' perspectives and lecturers' performance in relation to students' VLE implementation in Advanced Technological institutes, there were no empirical reports on VLE characteristics. The study looked into three aspects of VLE quality in this regard: service quality, information quality and system quality

The VLE characteristic's descriptive profiles of service quality, information quality, and system quality have been released. Only system quality, out of the three VLE attributes, has a substantial impact on students' VLE implementation. Students are driven to use their VLE in a pandemic situation because they believe its quality features, such as perceived ease of use, available aid, friendliness, security, speed, user and responsiveness, are well-versed. As a result, respondents stated that the VLE they use meets their expectations for system quality, and system quality has a big impact on how students use VLE.

The effect of Institutes supports on students' VLE implementation

Higher education institutions must provide outstanding user support and encourage students to use the system. Institutes should encourage the use of technology and explicitly define the technology's objective and importance to the institute's success. Only a small amount of study has looked into how institute support affects lecturers' and students' adoption and use of virtual learning technologies.
According to the findings of this study, institute support was found to be substantially associated to students' VLE implementation. According to the respondents, the institute's service for efficient VLE implementation should be of high quality. As a result of the analysis, the developed hypotheses about institute support and VLE implementation were found to be entirely supported.

To summarize, the data and discussion offered in the preceding paragraph have aided in answering one of the research questions and achieving one of the researches aims, namely, institution assistance does have an impact on students' VLE implementation.

\section{REFERENCES}

[1] G. H. E. Gay, "An assessment of online instructor e-learning readiness before, during, and after course delivery," J. Comput. High. Educ, vol. 28, no. 2, p. 199-220, 2016.

[2] M. F. Frimpon, "A Re-Structuring of the Critical Success Factors for E-Learning Deployment," Am. Int. J. Contemp. Res., vol. 2, no. 3, p. 115-127, 2012.

[3] L. B. B. a. R. N. Melo, "Towards a Reference Model for eLearning Governance," in PUC-RioInf.MCC20, 2014.

[4] M. V. B. P. Y. R. a. D. S. N. R. Mahoney, "Implementing an electronic learning management system for an ophthalmology residency program," BMC Med. Ed., vol. 16, 2016.

[5] R. I. a. H. D. Z. Nurakun Kyzy, "Learning management system implementation: a case study in the Kyrgyz," Interactive Learning Enviro., p. 1-13, 2018.

[6] B. Little, "The purchasing-and practical benefits-of a learning management system," Industrial and Comm. Training, vol. 47, p. 380-385, 2015.

[7] Y. P. a. I.-H. Jo, "Using log variables in a learning management system to evaluate learning activity using the lens of activity theory," Assessment \& Evaluation in Higher Ed., vol. 42, p. 531547, 2017.

[8] J. L. T. M. a. K. D. D. Walker, "Learning management system usage: perspectives from university instructors," Quarterly Rev. Dist. Ed., vol. 17, p. 41-50, 2016.

[9] K. Sriprasertpap, "The development of online training model for Srinakharinwirot university in Thailand," Procedia - Social and Behavioral Sciences," vol. 197, p. 1913-1917, 2015.

[10] H. B. a. F. Ozdamli, "Validating the instrument of web basedcollaborative learning competences using factor analysis," Social and Behavioural Sciences, vol. 15, pp. 3921 - 3926, 2011.

[11] G. M. a. M. B. T. Monahan, "Virtual reality for collaborative learning," Computers and Education, vol. 50, pp. $1339-1353$, 2008.

[12] R. M. R. H. Hamsiah Mohd Dahalan, "Development of WebBased Assessment in Teaching and Learning Management System (e-ATLMS)," Procedia - Social and Behavioral Sciences, vol. 9, pp. 244-248, 2010.

[13] C. C. \&. M. A. Flores, "COVID-19 and teacher education: a literature review of online teaching and learning practices," European Journal of Teacher Education, 2020.

[14] J. C. Philip E. Robinson, "An Online Learning Platform for Teaching, Learning, and Assessment of Programming," in 2017 IEEE Global Engineering Education Conference (EDUCON), Athens, Greece, 2017.

[15] J. C. Philip E. Robinson, "An Online Learning Platform for Teaching, Learning, and Assessment of Programming," in Global Engineering Education Conference (EDUCON), Athens, Greece, 2017.

[16] S. A. A. Khulood Aljuhani, "Information Quality of E-learning Systems in Saudi Arabia," in International Advanced Research Journal in Science, Engineering and Technology, 2018. 


\section{Volume XI, Issue I, January 2022| ISSN 2278-2540}

[17] J. Janossy, "Proposed Model for Evaluating C/LMS Faculty Usage in Higher Education Institutions.," in 13th Annual Instructional Technology Conference., Murfreesboro: Middle Tennessee State University, 2008

[18] G. D. a. C. Mahender, "A Review Paper on Text Summarization," International Journal of Advanced Research in Computer and Communication Engineering., pp. 3-10, 2016.

[19] Y. a. S. A. H. Husam Ali, "Automation Of Question Generation From Sentence," p. 2016.

[20] V. Jasmeet Singh and Gupta, "A systematic review of text stemming techniques,Artificial Intelligence Review," pp. 1-61, 2016.

[21] G. W. H. A. F. A. A., "A survey of text similarity approaches," International Journal of Computer Applications, vol. 68, no. 13, pp. 13-18, 2016.

[22] S. T. S. N. V. A. a. J. R. A. Shirude, "Automated Question Generation tool for structured data," International Conference on Advances in Computing, Communications and Informatics (ICACCI), 2015.

[23] A. B. B. A. Omarbekova, "Generation of Test Questions from RDF Files Using PYTHON and SPARQL," Journal of Physics: Conference Series., vol. 806, no. 1, 2017.

[24] T. C. L. C. P. Y. a. R. T. T. C. Lee, "Automatic question generation from childrens stories for companion chatbot," IEEE International Conference on Information Reuse and Integration (IRI), pp. 491-494, 2018

[25] J. S. a. F. L. T. Raynaud, "Thematic question generation over knowledge bases," IEEE/WIC/ACM International Conference on Web Intelligence (WI), pp. 1-8, 2018.

[26] H. \&. P. S. Mehlinger, "Technology and teacher education," in A guide for educators and policymakers. Boston, MA , Houghton Mifflin Company, 2002.

[27] A. Y. S. A. \&. S. J. Alsabawy, "IT infrastructure services as a requirement for e-learning system success," in Computer and Education, 2013, p. 431-451.
[28] A. H. V. \&. B. E. Ettinger, "E-learner experiences: learning from the pioneers," in Industrial and Commercial Training, 2005, p. 286-290

[29] T. Teo, "Modeling the determinants of pre-service teachers' perceived usefulness of elearning," in Campus-Wide Information Systems, 2011.

[30] V. W. K. \&. C. H. Thurmond, "Evaluation of student satisfaction: determining the impact of a web-based environment by controlling for student characteristics.," in The American Journal of Distance Education, 2002, pp. 89-169.

[31] K. Fee, "Delivering E-Learning:: A Complete Strategy for Design Application and Assessment," in London and Philadelphea, 2005.

[32] "Effective Use of Virtual Learning Environments," [Online]. Available: http://www.jiscinfonet.ac.uk/InfoKits/effective-use-ofVLEs. [Accessed 19 August 2020].

[33] "e-Learning glossary," [Online]. Available: http://www.learningcircuits.org/glossary.html. [Accessed 24 Auguest 2020].

[34] H. M. Selim, "E-learning critical success factors: An exploratory investigation of student," in International Journal of Technology Marketing, 2017.

[35] S. S. N. Mohamed Fathima Rashida1, "Undergraduates' Use Behavior of Learning Management Systems:," European Journal of Business and Management, vol. 10, p. 4, 2018.

[36] A. R. W. Seiyathu Mohammathu Murshitha, "A STUDY OF STUDENTS' PERSPECTIVES ON THE ADOPTION OF LMS AT UNIVERSITY OF KELANIYA.," 2016.

[37] A. Al-Azawei, "Predicting Learners' Performance in Virtual Learning Environment (VLE)," in International Journal of Emerging Technologies in Learning (iJET, 2020.

[38] N. A. A. M. A. A. R. Rahimah K, "Conceptual Model Of Virtual Learning Environment (VLE) Acceptance And Success : A Review From The Lecturers' Perspective," 2016. 